\title{
Analysis of students' quantitative literacy in human coordination system concept
}

\author{
Yuda Harianto, Saefudin, Eni Nuraeni \\ Department of Biology Education, Postgraduate School of Universitas Pendidikan Indonesia, \\ Setiabudi Street No. 229, Bandung 40154, Indonesia \\ hariantoyuda@student.upi.edu
}

\begin{abstract}
This study aimed to measure and analyze students' quantitative literacy (QL) in human coordination system concept. It involved 76 participants (16-17 years old) from the second grade of senior high school at two national schools in Subang, West Java, Indonesia. These participants consisted of 39 males and 37 female students. Their QL was assessed by four essay tests to examine their QL indicators including interpretation, representation, calculation, and analysis through coordination system in human issue. Their answers were analyzed by a QL rubric according to Association of American Colleges and University (AACU) assessment. QL achievement for each indicator was categorized into four levels. The analysis result showed that students' interpretation, representation, calculation, and analysis were at level 3,2,3, and 1, respectively. Based on data analysis, students' achievement in calculation, interpretation, and representation were categorized as the milestone (mediocre). Meanwhile, their analysis skill was classified as a benchmark or the lowest QL level.
\end{abstract}

Keyword: quantitative literacy, coordination system concept

\section{Introduction}

The twenty-first century is a world filled with quantitative information [1]. Today is the time when large amounts of information can be accessed on the internet. Most of this information is quantitative. With the increasing accessibility of data and news through the media and the internet, the citizen (especially the students) will be faced with many quantitative data and arguments that need to be processed and understood [2]. They should be prepared to analyze the information so that they can filter the data to make decisions in everyday life [3]. Many people sometimes overlook this quantitative aspect although it is important for them to apply it when working, studying, even while recreating in their free time [4]. The educational field, including biology education as life science, is also influenced by aspects of quantitative teaching as it evolves to accommodate the twenty-first century's challenge. The assumption that biology is a free science of mathematical elements still exists in the minds of students or even the teachers [5]. Biology subjects mostly discuss material that is qualitative and descriptive rather than quantitative [6]. Even in the last decade, the education practitioners have emphasized the teachers about how important it is for students to apply quantitative skills in the context of biology learning [7]. 
In general, biology teaching practice rarely involves mathematical principles. Research has shown that the fear of mathematics continues from primary school to college [5]. In fact, the integration between quantitative literacy (QL) and biology teaching requires students to apply their mathematical skills in biological issues [8]. QL is a part of science literacy. The Program for International Student Assessment (PISA), which focuses on the development of scientific literacy, defines QL as a person's ability to recognize and formulate problems into mathematical forms in everyday life [9]. The competence to use mathematical understanding is an important part of science literacy [8]. QL emphasized in mathematic application to analyze the scientific data and gain knowledge. It is synonymous with numeracy, quantitative reasoning and statistical literacy [10]. QL refers to the competency to interpret data and numbers in daily life [7]. The Association of American Colleges and University (AAC\&U) defines QL as a habit of thinking, competence and the comfort in working with numerical data [11]. Furthermore, Frith and Gunston define QL as the ability to manage situations or solve problems in practice, and involves responding to quantitative (mathematical and statistical) information that may be presented verbally, graphically, in tabular or symbolic form [12]. Based on QL rubrics issued by AAC\&U, there are six QL indicators including interpretation, representation, calculation, analysis, assumptions, and communication [11]. Achievements for each indicator are categorized into four levels: level 1 (benchmark/basic), 2-3 (milestone/mediocre), and 4 (Capstone/advanced). Indicators in this study were limited to test four indicators including interpretation, representation, calculation, and analysis because they are considered as the basic elements of QL.

There have been many studies that discuss QL profiles in biology content. In general, their research was focused on topics that already have practice activities due to many aspects of it could be developed for QL. Examples of their selected material are the respiratory system, digestive system, plant growth and development, plant anatomy, photosynthesis and environmental pollution. But, there has been no research that discusses QL profiles on highly conceptual material such as the human body coordination system. Therefore, this study aimed to measure and describe the students' QL profiles on it. Also this research aimed to find some content of this material that could be developed to train students' QL.

\section{Method}

This research used descriptive research method to measure and describe the quantitative literacy profile of students on the concept of human body coordination system. The learning process of it was observed to complement the results of data analysis. This research involved 76 participants (16-17 years old) from the second grade of senior high school at two national schools in Subang, West Java, Indonesia. These participants consisted of 39 male and 37 female students.

QL profiles of students were collected through four questions that come from a research case related to the coordination system (Figure 1). The four problems 
examined students' ability in interpretation, representation, calculation, and analysis of research data. The test was given after the students have finished their study on coordination system in the classroom. Once compiled, their answers were analyzed by QL rubric according to AAC\&U rubric values. There are four levels of QL achievement: Level 1 (basic level), Level 2-3 (Intermediate level) and Level 4 (advanced level). QL score represented the level that students could make at each indicator. The maximum score that could be achieved by students was 16. Students' QL profiles including the mean and the percentage of level achievement for all four indicators.

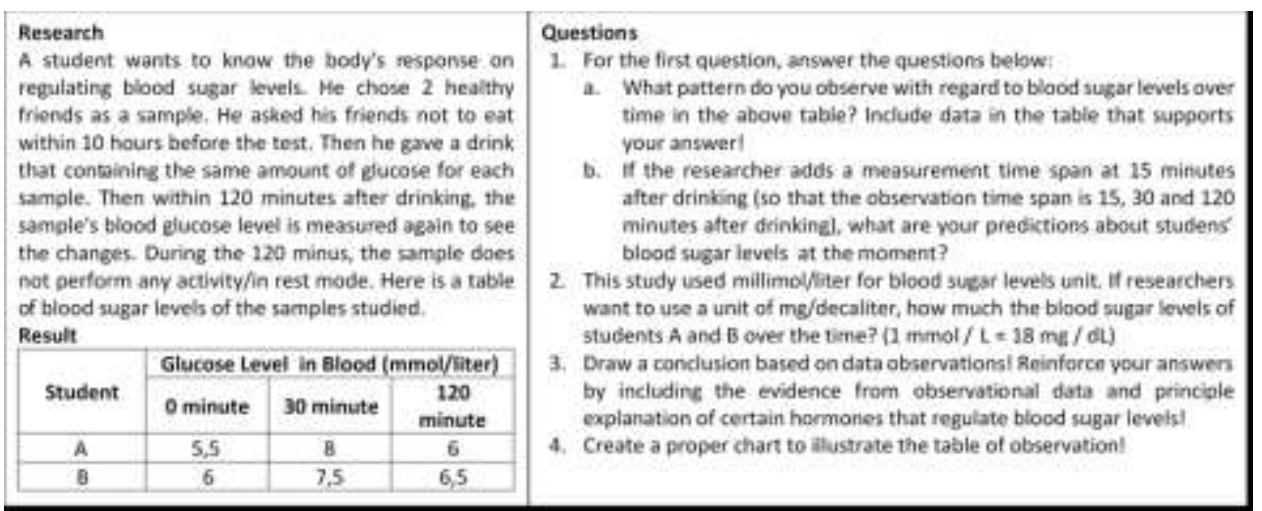

Figure 1. QL test based on human coordination system issue

\section{Results and Discussion}

The results of this study describe the students' QL achievement that tested through several questions from human's coordination system case. The result of descriptive analysis provided the mean score and the percentage of students' QL level for each indicator.

\subsection{Descriptive Analysis Result}

Table 1. Statistical test result

\begin{tabular}{cccc}
\hline $\mathrm{N}=76$ & Mean & Minimum Score & Maximum Score \\
\hline Total LK & 7.9 & 2.5 & 13 \\
Interpretation & 2.6 & 1 & 4 \\
Representation & 1.5 & 0 & 4 \\
Calculationi & 2.7 & 0 & 4 \\
Analysis & 1.1 & 0 & 3.5 \\
\hline
\end{tabular}

The mean of students' QL score reached 7.94 or 8 if rounded as shown in Table 1. It was considered as modest level if compared to the best mean score that could be obtained (max mean $=16)$. Furthermore, the calculation indicator was the best QL accomplishment in this research while the analysis was the lowest QL achievement. The rating of indicators from the best to the worst was calculation, interpretation, representation, and analysis. The interpretation indicator had a better minimum score than the others that could reach a score one while the maximum score of the analysis indicator could not reach score four like any other indicator. 
Then the percentage of QL achievement level for each indicator is shown in Figure 2. Students' score indicated their level on it. For example, a student who got score one was at first level (level 1) and so on. The interpretation test result was dominated by student who got score two (36\%). Then at the representation, mostly students $(61 \%)$ were at first level. Later, the students who attained the third level was supreme at calculation assessment (51\%). In contrast, analysis test result were dominated by first level student (71\%). The zero level on each indicator was given if student empties the answer sheet.

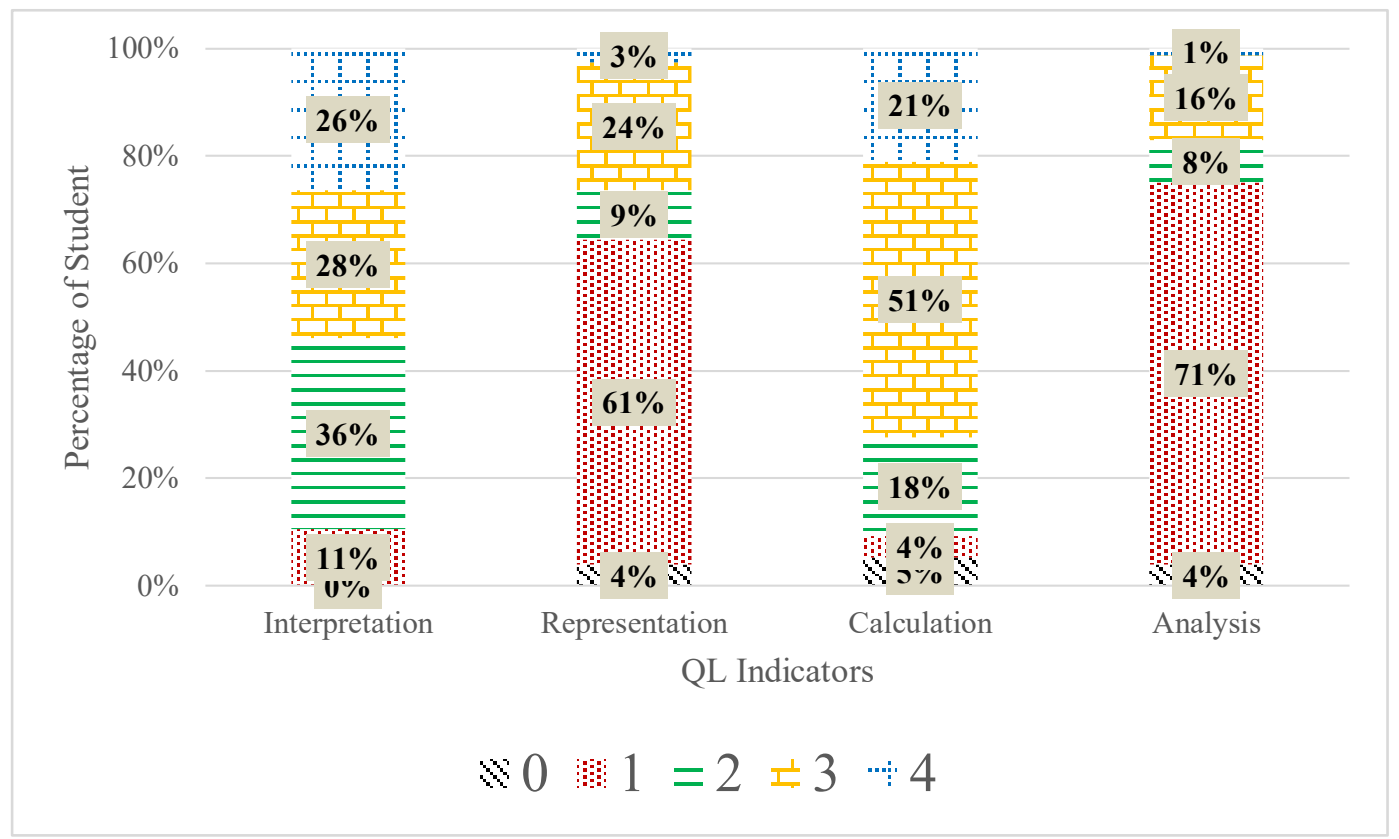

Figure 2. Percentage of QL level achievement for each indicator

\subsubsection{Interpretation Achievement.}

The interpretation refers to the competency to describe mathematically presented information (equations, graphs, diagrams, tables) [11]. It was tested by the first question as shown in Figure 1. Students were asked to explain the pattern of data in the table of blood glucose levels observations. Also, students were asked to predict the future of it. If students understood this data, then they would have no trouble predicting the future of it. The analysis result showed that the second level QL students were dominant in interpretation's test. It means that students could explain it and make prediction, but their answer was not correct yet. In general, students explained data in reverse pattern. For example, they interpreted it as an increasing pattern. In fact, it was up and down pattern. So their prediction was not relevant due to their wrong understanding of data patterns. Only a small percentage of students could answer both aspects appropriately. This result indicated that students were not used to reading tables or graphs. 


\subsubsection{Representation Achievement.}

Representation is the competency to convert relevant information into mathematical forms (equations, graphs, diagrams, tables) [11]. It required students to create a chart based on the observation table (fourth question, Figure 1). The results showed that most students were still at first level ability. Most students were able to make it but still not proper. Students tended to make bar chart rather than line chart for continuous data. There were very few students could create it appropriately with complete attributes. This aspect is important to be taught due to the understanding of representation will help them in the future to describe the research data.

\subsubsection{Calculation Achievement.}

The calculation is the competency to do the mathematical estimation [11]. It required students to change the unit of blood glucose levels from $\mathrm{mmol} / \mathrm{L}$ to $\mathrm{mg} / \mathrm{dL}$ (second question, Figure 1). Comparison between these units had been informed. Most students were able to alter the unit of blood glucose levels appropriately (third level achievement). They just did not include the calculation steps in answer to reaching the fourth level. A small number of students were still at the first level due to inaccuracy in the calculation process.

\subsubsection{Analysis Achievement.}

The analysis is the competency to make judgments and draw proper conclusions based on quantitative data [11]. It required students to make conclusion from the result of research (third question, Figure 1). Most students were able to make it and show evidence of quantitative data but still not correct. They tended to make conclusions that were not related to the research objective. It indicated that they had not understood the purpose of the study which is the main case of the question. A minority of students who were at the fourth level was able to make proper conclusions. They had included quantitative evidence to warrant their conclusion and linking data with biological concepts accurately. Otherwise, the majority of students just wrote down the name of a hormone that regulates blood glucose levels. They could not explain its role in balancing the level of blood glucose.

\subsection{Discussion}

The results of data analysis showed that students' QL achievement (mean score) was considered as modest level. It was just half of the highest score. In other words, it was only at level 2 or mediocre. This result was not much different from other studies that measured QL profile in the initial phase/natural condition without any treatment. Students' QL achievement from the highest to the lowest were calculation, interpretation, representation, and analysis.

Based on data results, students' feat on calculation, interpretation, and representation were at the second level (milestone/mediocre) while their ability on analysis was at the first level (lowest level). The results were consistent with another research on different 
materials that students had difficulty in applying aspects of the QL in the context of biological problems [7]. The order of QL's indicators achievement was also relevant to other research results that the calculation was the most mastered indicator by students while the analysis was the least [13] [14]. It confirmed the theory that students could do better in QL test if it's context-free biology (such as calculation, interpretation and representation test) rather than in integrated context (analysis) [7]. On analysis test, they had difficulty in connecting data onto proper biological concepts. It indicated that they had a low level of reasoning. Whereas, QL emphasizes higher analysis through basic mathematical understanding [1]. However, it was acceptable due to researchers could not assume that students were ready to use quantitative reasoning in a biological context [15].

Students' QL achievement was relevant to their learning process in the classroom. First, QL aspect had not been applied to human coordination concept learning. Then, students were familiar with the case of biology that emphasize content understanding only. Afterward, QL has not become a habit of thinking for students yet. During coordination system learning in the classroom, concepts were delivered through the presentation. It was presented by groups of student. They presented it according to textbooks without any further explanation. In the beginning, the teacher had provided a broad overview of coordination system concept, but that was certainly not enough. Even though, students could have invited to discuss some cases or research results related to the coordination system, so there is an opportunity for the teacher to develop QL aspect.

In point of fact, QL could be brought into the learning of coordination system in human. The sympathetic and parasympathetic from the nervous system could take a case of a person's pulse rate after drinking an energized drink over a period. Changes in pupil diameter, when highlighted by light, could be discussed in the human's sensory system concept. In the endocrine system learning, students can perform a practice to test the effect of sweet beverages consumption to the glucose level in their blood (Figure 1). Also, graphs that discuss abnormalities in the endocrine system such as glucose level graph from diabetic patients at a specific time could be used as a material for developing QL aspect. The development of learning strategies that discuss those cases could be used as future research material to test its influence on students' QL improvement. The development of QL-based practice also needs to be developed on human coordination system concept. As an assumption, implementation of learning strategies that accommodate both procedural and factual knowledge is a good way to practice QL aspect [16]. At this point, QL plays an important role to prepare future scientists who can think rigorously about their assumptions, experiments, and conclusions [17]. Today, the field of biology has increasingly relied on an interdisciplinary approach to addressing complex biological problems, and this approach usually requires significant quantitative analysis [18]. Furthermore, integrating QL into content could highly support teaching and learning on the difficult topics such as the nature of science and the construction of scientific knowledge [15]. 


\subsection{Conclusion}

The findings of this study has yielded some conclusions. First, the mean of students' QL accomplishment was at the second level (mediocre). Second, QL indicators from the highest to the lowest was calculation, interpretation, representation, and analysis. Third, there are some concepts/materials in human coordination system could be discussed as QL issues. Fourth, the learning strategies that applying aspects of QL in the case of biology needs to be further developed.

\section{References}

[1] Steen L A 2001 In Mathematics and Democracy: The Case for Quantitative Literacy (Princeton: National Council on Education and the Disciplines)It is better you use citation applications such as Mendeley, Zotero, RefWorks, Endnote, etc. The layout style is like this sentence.

[2] Dingman S W 2010 Quantitative Reasoning in the Contemporary World, 1: The Course and Its Challenges Numeracy 3 pp 1-16

[3] Elrod S 2014 Quantitative Reasoning: The Next "Across the Curriculum" Movement Peer Review Journal 16 pp 1-11

[4] Kemp M 2003 Proc. Int. Conf. in Mathematics Education (Brno) vol 6 (Palermo: Dipmat of Universita Degli Studi Di Palermo) pp 144-148

[5] Stafford R and Williams R 2014 Teaching Basic Numeracy, Predictive Models And Socioeconomics To Marine Ecologist Through Bayesian Belief Research Gate Journal 3 pp 1-6

[6] Thompson K V, Nelson K C, Marbach-Ad G, Keller M, and Fagan W F 2010 Online Interactive Teaching Modules Enhance Quantitative Proficiency of Introductory Biology Students Life Sciences Education Journal 9 pp 277-283

[7] Hester S, Buxner S, Elfring L and Nagy L 2013 Integrating Quantitative Thinking into an Introductory Biology Course Improves Students Mathematical Reasoning in Biological Contexts Life Science Education Journal 13 pp 54-64

[8] Baumgartner E, Biga L, Bledsoe K, Dawson J, Grammer J, Howard A and Snyder J 2015 Exploring Phytoplankton Population Growth To Enhance Quantitative Literacy: Putting Vision \& Change Into Action National Association of Biology Teachers Journal 77 pp 265-272

[9] Organization For Economic Co-Operation And Development 2007 Science Competencies for Tomorrow's World vol 1 (Paris: OECD) p 21

[10] Beaudrie B 2010 The Numeracy Action Plan: The Case for Quantitative Literacy in The State of New Hampshire (Plymouth: New Hampshire Impact Center)

[11] Association of American Colleges \& Universities (AAC\&U) 2009 Quantitative Literacy Value Rubric https://www.aacu.org/ Online: https://www.aacu.org/value/rubrics/quantitative-literacy

[12] Frith V and Gunston G 2011 Towards Understanding The Quantitative Literacy Demands Of A First Year Medical Curriculum African Journal Of Health Professions Education 3 pp 19-23 
[13] Munawaroh M 2014 Analisis Literasi Kuantitatif Siswa SMA Dalam Konsep Pertumbuhan Dan Perkembangan Tumbuhan upi.edu Online: http://repository.upi.edu/7078/

[14] Harianto Y 2015 Pengaruh Model Pembelajaran Berbasis Proyek Terhadap Pencapaian Literasi Kuantitatif Siswa SMA Pada Konsep Monera upi.edu Online: http://repository.upi.edu/22336/

[15] Speth E B, Momsen J L, Moyerbrailean G A, Ebert-May D, Long T M, Wyse S and Linton D 2010 Infusing Quantitative Literacy into Introductory Biology Life Science Education Journal 9 pp 323-332

[16] Nuraeni E, Redjeki S, Riandi and Rahmat A 2015 Perkembangan Literasi Kuantitatif Mahasiswa Biologi Dalam Perkuliahan Anatomi Tumbuhan Berbasis Dimensi Belajar Jurnal Ilmu Pendidikan 21 pp 127-135

[17] Wallace D 2016 Parts of the Whole: Teaching Quantitative Reasoning in the Predator-Prey Model Numeracy 9 pp 1-7

[18] Hoffman K, Leupen S, Dowell K, Kephart K, and Leips J 2016 Development and Assessment of Modules to Integrate Quantitative Skills in Introductory Biology Courses Life Sciences Education Journal 15 pp 1-12 